\title{
Composição corporal e eficiência de utilização de nutrientes por pacus alimentados com ração suplementada com cromo trivalente
}

\author{
Rodrigo Yudi Fujimoto ${ }^{(1)}$, Marcello Pardi de Castro ${ }^{(2)}$, Claucia Aparecida Honorato ${ }^{(3)}$ e Flávio Ruas de Moraes $^{(2)}$ \\ (1)Universidade Federal do Pará, Alameda Leandro Ribeiro, s/no, CEP 68600-000 Bragança, PA. E-mail: ryfujim@hotmail.com (2)Universidade \\ Estadual Paulista (Unesp), Fac. de Ciências Agrárias e Veterinárias, Dep. de Patologia Veterinárias, Rod. de acesso Paulo Donato Castelane, \\ s/no, CEP 14870-000 Jaboticabal, SP. E-mail: castromarcello@hotmail.com, fruas@fcav.unesp.br (3)Unesp, Centro de Aqüicultura. \\ E-mail: clauciahonorato@yahoo.com.br
}

\begin{abstract}
Resumo - O objetivo deste trabalho foi avaliar a composição corporal e a eficiência de utilização de nutrientes por pacus alimentados com dieta suplementada com cromo trivalente e mantidos em duas densidades de estocagem. O delineamento experimental foi inteiramente ao acaso com 24 tratamentos, em esquema fatorial: quatro níveis de cromo na ração $\left(0,6,12,18 \mathrm{mg} \mathrm{kg}^{-1}\right)$, duas densidades de estocagem $\left(4 \mathrm{e} 20 \mathrm{~kg} \mathrm{~m}^{-3}\right)$ e três períodos de avaliação (30, 60 e 90 dias) com quatro repetições. Foram observados aumentos significativos na eficiência de retenção de proteína bruta e na porcentagem de proteína bruta na carcaça, diminuição de eficiência de retenção de gordura e menores valores de porcentagem de gordura na carcaça dos pacus alimentados com ração suplementada. O nível de cromo de $6 \mathrm{mg} \mathrm{kg}^{-1}$ foi suficiente para possibilitar, na menor densidade, o maior acúmulo de proteína e menor teor de gordura na carcaça, ao passo que, na maior densidade, a exigência de cromo foi mais alta (12 $\left.\mathrm{mg} \mathrm{kg}^{-1}\right)$, para obtenção de resultados semelhantes. Pacus alimentados com dietas suplementadas com cromo apresentaram carne mais magra, com menor teor de gordura, até 60 dias de experimento.
\end{abstract}

Termos para indexação: Piaractus mesopotamicus, densidade de estocagem, deposição de proteína, teor de gordura.

\section{Body composition and nutrient efficiency use by pacus fed on ration supplemented with chromium}

\begin{abstract}
The objective of this work was to evaluate body composition as well as nutrient efficiency use by pacus fed on diet supplemented with chromium at two stocking densities. The experimental design was completely randomized with 24 treatments, in factorial scheme: four levels of chromium in the diet $\left(0,6,12\right.$, and $\left.18 \mathrm{mg} \mathrm{kg}^{-1}\right)$, two stocking densities (4 and $20 \mathrm{~kg} \mathrm{~m}^{-3}$ ) and three periods (30,60 and 90 days). Increases in efficiency of crude protein retention and in percentage of crude protein and decrease in efficiency of fat retention and smaller values of fat percentage in the carcass were observed. In the smallest density, the level of $6 \mathrm{mg} \mathrm{\textrm {kg } ^ { - 1 }} \mathrm{of} \mathrm{chromium} \mathrm{was}$ enough to make possible the higher accumulation of protein and smaller fat concentration in the carcass. In the density of $20 \mathrm{~kg} \mathrm{~m}^{-3}$, the need of chromium was higher, $12 \mathrm{mg} \mathrm{kg}^{-1}$, to obtain similar results. Pacus fed on diet supplement with chromium present lean meat, with smaller fat concentration, until 60 days of experiment.
\end{abstract}

Index terms: Piaractus mesopotamicus, stocking density, protein deposition, fat level.

\section{Introdução}

O cromo é considerado elemento em transição, encontrado naturalmente em estado oxidado, nas formas tri e hexavalente. A última é tóxica e a primeira é relevante do ponto de vista nutricional, pois é estável, tem baixa toxicidade e apresenta ampla margem de segurança (Cazes, 1999). Este mineral atua no metabolismo de glicose e lipídios (Sano et al., 1999) e a suplementação dietética com esse microelemento tende a reduzir os efeitos nocivos do estresse em espécies domésticas (Mowat, 1997). Segundo Fujimoto et al. (2005), pacus submetidos a estresse por alta densidade de estocagem $\left(20 \mathrm{~kg} \mathrm{~m}^{-3}\right)$ e alimentados com ração suplementada com cromo trivalente $\left(18 \mathrm{~g} \mathrm{~kg}^{-1}\right)$ apresentaram diminuição de cortisol plasmático, indicando redução do estresse após sete dias de alimentação. 
Shiau \& Lin (1993) observaram que tilápias híbridas (Oreochromis niloticus x O. aureus) alimentadas com ração suplementada com cromo ganharam mais peso, apresentaram maior deposição de proteína e menor deposição de gordura. A suplementação com cromo potencializa a ação da insulina e inibe a gliconeogênese, com ganho de eficiência na utilização de proteína e carboidrato (Hertz et al., 1989).

O pacu, Piaractus mesopotamicus (Holmberg, 1887), é comercialmente interessante devido a sua adaptação ao cativeiro, tecnologia de reprodução conhecida, boa aceitação de ração e carne saborosa para consumo. Porém, o pacu é classificado como pescado gordo, pois sua composição corporal contém alto teor de gordura, com cerca de 8 a $10 \%$ de lipídeos na carcaça (Alves, 1999; Stech, 1999).

Modificações qualitativas e quantitativas da ração podem alterar a composição corporal dos peixes (Reinitz et al., 1988 citado por Stech, 1999). Observou-se que o cromo potencializa a ação da insulina, via fator de tolerância à glicose (GTF) (Commitee on Animal Nutrition, 1997) em ratos (Hasten et al., 1997), frangos (Hossain et al., 1998), ruminantes e suínos (Commitee on Animal Nutrition, 1997). A insulina regula a produção de energia e a deposição de tecido muscular (Hossain et al., 1998). A ação potencializadora do cromo sobre a insulina permite maior captação de glicose pelas células, diminuindo sua disponibilidade excessiva para o metabolismo em gordura (Hossain et al., 1998).

Em humanos, o cromo inibe indiretamente as enzimas de síntese de ácido graxo, responsáveis pela lipogênese, modificando o armazenamento de triglicerídeos mediados pela insulina, resultando em menor deposição de gordura (Kaats et al., 1998), tendo também um efeito positivo sobre a utilização e incorporação de aminoácidos e na síntese de proteínas, melhorando a transcrição do RNA (Okada et al., 1984).

Trutas (Oncorhynchus mikiss) alimentadas com ração suplementada com $0,5 \mathrm{mg} \mathrm{kg}^{-1}$ de cromo, na forma de quelato, não diferiram do grupo-controle (não suplementado) quanto à retenção de proteína e de gordura (Bureau et al., 1995). Pan et al. (2003) não encontraram diferença significativa na composição corporal de tilápias híbridas (O. niloticus x $O$. aureus), criadas em sistema aberto de circulação de água, suplementadas com até $2 \mathrm{mg}$ de cromo picolinato por quilograma de ração. Entretanto, os autores verificaram efeito do cromo sobre a composição da carcaça, quando os peixes foram criados em sistema de recirculação (fechado), o que permitiu a bioacumulação adicional do nutriente, aumentando as respostas e melhorando a qualidade de carcaça.

O objetivo deste trabalho foi avaliar a composição corporal e a eficiência de utilização de nutrientes em pacus alimentados com ração suplementada com cromo trivalente e mantidos em duas densidades de estocagem.

\section{Material e Métodos}

O trabalho foi conduzido na Universidade Estadual Paulista, de março a abril de 2003. A duração do período experimental foi de 90 dias e foram utilizados 32 tanques de cimento com capacidade de $500 \mathrm{~L}$, abastecidos continuamente com água de poço artesiano. O fluxo foi adequado para cada densidade e o escoamento foi realizado por sifonamento do fundo do tanque.

Previamente aos ensaios, pacus jovens, com $100 \mathrm{~g}$ de peso médio, foram acondicionados nos tanques, na densidade de $11 \mathrm{~kg} \mathrm{~m}^{-3}$, por um período de aclimatação de dez dias. Após esse período, os peixes foram distribuídos ao acaso, nas densidades iniciais de estocagem de 4 e $20 \mathrm{~kg} \mathrm{~m}^{-3}$, segundo Rotllant et al. (1997) e Brum (2003).

Os peixes foram alimentados com ração básica com $26 \%$ de PB e $4.100 \mathrm{kcal}$ de EB (Tabela 1). A essa ração, foram adicionadas quatro concentrações de cromo

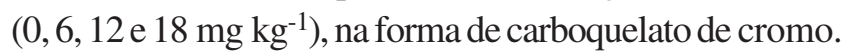

Tabela 1. Fórmula e composição básica das rações ${ }^{(1)}$.

\begin{tabular}{lc}
\hline Ingredientes & Porcentagem \\
\hline Farinha de peixe & 13,0 \\
Farelo de soja & 23,0 \\
Farelo de trigo & 21,0 \\
Milho moído & 25,0 \\
Farelo de arroz & 16,0 \\
Óleo de soja & 1,0 \\
Suplemento vitamínico e mineral ${ }^{(1)}$ & 1,0 \\
\hline Composição calculada ${ }^{(2)}$ & \\
$\quad$ Proteína bruta (\%) & 26,0 \\
$\quad$ Extrato etéreo (\%) & 6,23 \\
$\quad$ Fibra bruta (\%) & 6,25 \\
$\quad$ Energia bruta (kcal por kg de ração) & 4.100 \\
\hline Relação Ca:P & $1,45: 1$ \\
\hline
\end{tabular}

(1)Composição do suplemento mineral e vitamínico (nutriente por $\mathrm{kg}$ ): Fe, $15.000 \mathrm{mg}$; Cu, $5.000 \mathrm{mg}$; I, $500 \mathrm{mg}$; Mn, $17.000 \mathrm{mg}$; $\mathrm{Zn}, 12.000 \mathrm{mg}$; Se, $70 \mathrm{mg}$; veículo, $1.000 \mathrm{~g}$; vit. A, $12.000 \mathrm{UI}$; vit. D3, $1.500 \mathrm{UI}$; vit. E, $50 \mathrm{mg}$; vit. K, $4 \mathrm{mg}$; vit. B12, $7 \mathrm{mg}$; vit. B2, $7 \mathrm{mg}$; vit. B5, $60 \mathrm{mg}$; vit. B3, $120 \mathrm{mg}$; cloreto de colina, $600 \mathrm{mg}$; metionina, $700 \mathrm{mg}$; vit. C, $300 \mathrm{mg}$; antioxidante, $500 \mathrm{mg}$; veículo, $1.000 \mathrm{~g}$; premix isento de cromo. ${ }^{(2)}$ Composição calculada com base nas análises dos ingredientes (Association of Official Analytical Chemists, 1984). 
Devido à quantidade relativamente pequena de mineral adicionada, foi preparada uma pré-mistura com $10 \mathrm{~kg}$ da ração basal, antes de se homogeneizar com o restante da ração. Após homogeneização, as dietas foram peletizadas e estocadas a $-18^{\circ} \mathrm{C}$, até o momento do uso.

Os peixes foram alimentados uma vez ao dia, sempre às $9 \mathrm{~h}$, à vontade, até que não houvesse mais procura pelo alimento. $\mathrm{Na}$ análise de composição corporal, antes do início do experimento, foram coletados aleatoriamente 20 peixes e, ao final, 16 peixes de cada tratamento, sendo quatro de cada parcela, que foram conservados a $-4^{\circ} \mathrm{C}$ (Stech, 1999). O material resultante foi moído e secado à temperatura de $105^{\circ} \mathrm{C}$ até peso constante, para análise de matéria seca, proteína bruta e extrato etéreo, segundo Association of Official Analytical Chemists (1984), de acordo com as seguintes equações: eficiência de retenção $(E R): E R=[(M$ final $x$ peso final $)$ ( $\mathrm{M}$ inicial x peso inicial)/M ingerida]100; porcentagem no ganho de peso (\%GP): \%GP = [(M final - peso médio final)(M inicial - peso médio inicial)/peso final - peso inicial]100; em que M é o teor médio (\%) de proteína ou extrato etéreo corporal dos peixes na matéria seca ou na matéria original, e peso final e inicial referem-se aos pesos do início e final de cada período de coleta.

$\mathrm{O}$ experimento foi conduzido em delineamento inteiramente casualizado, com 24 tratamentos, em esquema fatorial: quatro concentrações de cromo na ração $\left(0,6,12\right.$ e $\left.18 \mathrm{mg} \mathrm{kg}^{-1}\right)$, duas densidades de estocagem (4 e $20 \mathrm{~kg} \mathrm{~m}^{-3}$ ), três épocas de coleta (30, 60 e 90 dias), com quatro repetições.

Os dados foram submetidos à análise de variância e as médias foram comparadas pelo teste de Tukey, a 5\% de probabilidade, quando os valores de $\mathrm{F}$ indicaram diferenças significativas $(\mathrm{p}<0,05)$. Os dados que não apresentaram distribuição normal foram transformados em $\log \mathrm{x}$ ou $\operatorname{arc} \operatorname{sen}(\mathrm{x} / 100)^{0,5}$. Na transformação dos dados de extrato etéreo, foi somado o fator 100, devido ao baixo valor dos dados originais.

\section{Resultados e Discussão}

Peixes alimentados com ração suplementada com cromo apresentaram aumento nos teores de proteína da carcaça, e houve interação entre a densidade de estocagem e época de coleta (Tabela 2). Nos peixes alimentados com ração suplementada, a época de coleta e o nível de cromo interferiram nos teores de extrato etéreo da carcaça e, de modo geral, houve aumento no teor protéico e diminuição no teor de gordura da carcaça. Segundo Okada et al. (1984), o cromo tem efeito positivo sobre a utilização e incorporação de aminoácidos e na síntese de proteínas que atuam no RNA mensageiro, proporcionando carcaças com maior teor de proteína.

Tabela 2. Médias e análise de variância de proteína bruta na matéria seca de carcaça (PBMS, em \%), teor de proteína bruta na matéria original (PBMO, em \%), teor de extrato etéreo na matéria seca de carcaça (EEMS, em \%), teor de extrato etéreo na matéria original (EEMO, em \%) e teor de matéria seca (MS, em \%) de juvenis de pacus alimentados com dietas suplementadas com diferentes concentrações de cromo, em duas densidades de estocagem ${ }^{(1)}$.

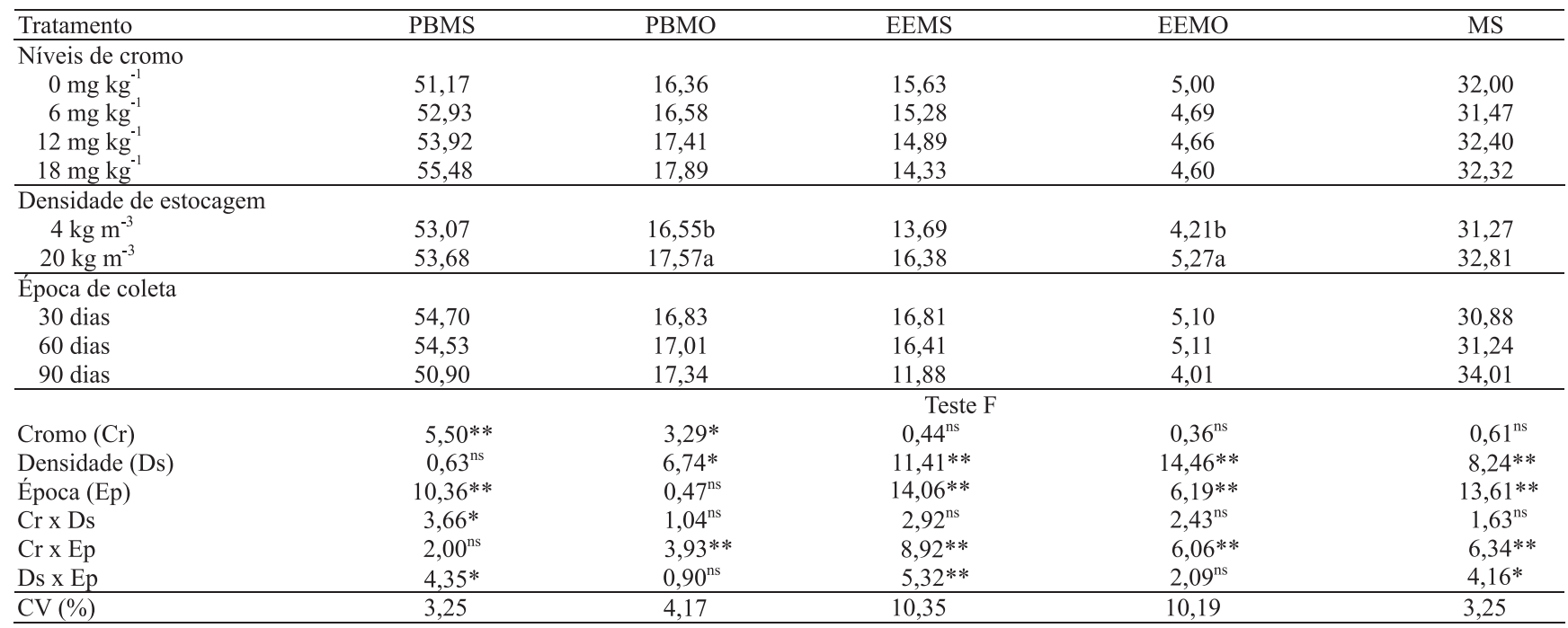

${ }^{(1)}$ Médias seguidas de mesma letra não diferem entre si pelo teste de Tukey, a $5 \%$ de probabilidade; dados transformados em arc sen (x/100) ${ }^{0,5}$.

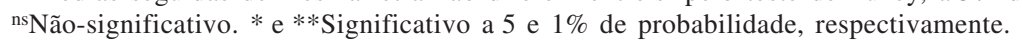


Em peixes alimentados com dietas suplementadas com 12 e $18 \mathrm{mg} \mathrm{kg}^{-1}$ de cromo, as carcaças apresentaram maior teor de proteína no final do período experimental. Essa variável não se alterou em peixes suplementados com níveis mais baixos. O nível de $18 \mathrm{mg} \mathrm{kg}^{-1}$ de cromo possibilitou aumento do teor protéico na carcaça nos primeiros 30 dias de experimento (Tabela 3). Por sua vez, peixes submetidos a dietas suplementadas com os níveis de 6 e $12 \mathrm{mg} \mathrm{kg}^{-1}$ apresentaram diminuição dos teores de gordura na carcaça ao final do experimento, sendo que o nível de $12 \mathrm{mg} \mathrm{kg}^{-1}$ possibilitou a diminuição de gordura aos 60 dias de experimento (Tabela 3). Kaats et al. (1998) afirmaram que, em humanos, o cromo age indiretamente nas enzimas de síntese de acido graxo, que são responsáveis pela lipogênese, inibindo-as e atuando no armazenamento de triglicerídeos mediados pela insulina, resultando em menor deposição de gordura. Além disso, o cromo tem efeito positivo sobre a utilização e incorporação de aminoácidos e na síntese de proteínas, melhorando a transcrição do RNA. Todavia são necessários estudos suplementares sobre esse tipo de ação em peixes (Okada et al., 1984).

A análise de variância dos dados de eficiência de retenção de proteína bruta (ERPB) e de extrato etéreo (EREE) indicou diferença significativa $(\mathrm{p}<0,05)$ nos peixes com dietas suplementadas com cromo (Tabela 4). Os peixes alimentados com a ração suplementada com $12 \mathrm{mg} \mathrm{kg}^{-1}$ de cromo apresentaram melhor eficiência de retenção de proteína bruta e maior porcentagem de proteína bruta no ganho de peso, indicando maior produção de tecido muscular. Esse efeito pode ser atribuído à ação potencializadora do cromo sobre a

Tabela 3. Efeitos de interação entre as concentrações de cromo e as épocas de coleta sobre o teor de proteína bruta na matéria original (PBMO, em \%) e teor de extrato etéreo na matéria original (EEMO, em \%) em juvenis de pacus ${ }^{(1)}$.

\begin{tabular}{cccc}
\hline Níveis de cromo & 30 dias & 60 dias & 90 dias \\
\hline & & PBMO & \\
$0 \mathrm{mg} \mathrm{kg}^{-1}$ & $16,91 \mathrm{Ab}$ & $16,85 \mathrm{Aa}$ & $15,32 \mathrm{Ac}$ \\
$6 \mathrm{mg} \mathrm{kg}$ & $16,94 \mathrm{Ab}$ & $16,95 \mathrm{Aa}$ & $15,84 \mathrm{Abc}$ \\
$12 \mathrm{mg} \mathrm{kg}^{-1}$ & $15,71 \mathrm{Bb}$ & $16,78 \mathrm{Ba}$ & $19,76 \mathrm{Aa}$ \\
$18 \mathrm{mg} \mathrm{kg}^{-1}$ & $17,77 \mathrm{Aa}$ & $17,45 \mathrm{Aa}$ & $18,46 \mathrm{Aab}$ \\
\hline & & EEMO & \\
$0 \mathrm{mg} \mathrm{kg}^{-1}$ & $4,20 \mathrm{Bb}$ & $5,80 \mathrm{Aa}$ & $4,00 \mathrm{Ba}$ \\
$6 \mathrm{mg} \mathrm{kg}^{-1}$ & $5,55 \mathrm{Aa}$ & $5,06 \mathrm{ABab}$ & $3,36 \mathrm{Ba}$ \\
$12 \mathrm{mg} \mathrm{kg}^{-1}$ & $5,43 \mathrm{Aab}$ & $4,05 \mathrm{Bb}$ & $3,50 \mathrm{Ba}$ \\
$18 \mathrm{mg} \mathrm{kg}^{-1}$ & $4,11 \mathrm{Ab}$ & $5,07 \mathrm{Aab}$ & $4,62 \mathrm{Aa}$ \\
\hline
\end{tabular}

(1)Médias seguidas por letras iguais, minúsculas nas colunas e maiúsculas nas linhas, não diferem entre si pelo teste de Tukey, a 5\% de probabilidade. insulina, responsável pela regulação da produção de energia e deposição de músculo (Mordenti et al., 1997; Hossain et al., 1998). Valores de ERPB acima de 15\% também foram encontrados em pacus jovens (180 g) alimentados com rações contendo soja com diferentes processamentos para inativação do fator antinutricional (Stech, 1999). Alves (1999) encontrou valores menores de ERPB (18-28\%) em pacus alimentados com ração contendo diferentes concentrações de lipídeos. Esses resultados foram semelhantes à ERPB de pacus não suplementados com cromo $(17,98 \%)$ neste trabalho, o que demonstra que a suplementação é relevante como poupadora de proteína. Esse efeito poupador é benéfico para a sustentabilidade da piscicultura, pois possibilita diminuição do impacto ambiental e redução de custos de produção (Figueiredo-Garutti, 1996).

Neste trabalho, foram encontrados valores superiores de ERPB $(46,13 \%)$ e proteína bruta no ganho de peso (PGP) $(33,4 \%)$, nos peixes alimentados com ração suplementada com $12 \mathrm{mg} \mathrm{kg}^{-1}$ de cromo, sugerindo maior eficiência de utilização da fração protéica (Tabela 4). Shiau \& Liang (1995) observaram aumento na taxa de deposição de proteína em tilápias (O. niloticus) suplementadas com $0,5 \%$ de óxido de cromo. Quanto à retenção de proteína e de gordura, trutas (O. mikiss) suplementadas com $0,5 \mathrm{mg} \mathrm{kg}^{-1}$ de cromo, na forma de quelato, não apresentaram diferenças em relação ao grupo-controle (Bureau, 1995).

Tabela 4. Médias e análise de variância da eficiência de retenção de proteína bruta (ERPB, em \%), eficiência de retenção de extrato etéreo (EREE, em \%), proteína bruta no ganho de peso (PGP, em \%), extrato etéreo no ganho de peso (EEGP, em \%) de juvenis de pacus alimentados com dietas suplementadas com diferentes concentrações de cromo, em duas densidades de estocagem ${ }^{(1)}$.

\begin{tabular}{lcccc}
\hline Tratamento & ERPB & EREE & PGP & EEGP \\
\hline Níveis de cromo & & & \\
$\quad 0 \mathrm{mg} \mathrm{kg}^{-1}$ & $17,98 \mathrm{~b}$ & 90,00 & $10,44 \mathrm{~b}$ & 90,00 \\
$\quad 6 \mathrm{mg} \mathrm{kg}^{-1}$ & $20,90 \mathrm{~b}$ & 62,15 & $13,04 \mathrm{~b}$ & 82,22 \\
$12 \mathrm{mg} \mathrm{kg}^{-1}$ & $46,13 \mathrm{a}$ & 61,57 & $33,44 \mathrm{a}$ & 79,35 \\
$18 \mathrm{mg} \mathrm{kg}^{-1}$ & $31,77 \mathrm{ab}$ & 86,78 & $21,05 \mathrm{ab}$ & 88,90 \\
\hline Densidade de estocagem & & \multicolumn{3}{c}{} \\
$\quad 4 \mathrm{~kg} \mathrm{~m}^{-3}$ & 27,28 & 67,93 & 18,14 & 83,09 \\
$20 \mathrm{~kg} \mathrm{~m}^{-3}$ & 26,84 & 82,32 & 20,85 & 87,14 \\
\hline & \multicolumn{4}{c}{ Teste $\mathrm{F}$} \\
Cromo (Cr) & $9,70^{* *}$ & $42,83^{* *}$ & $15,03^{* *}$ & $44,62^{* *}$ \\
Densidade (Ds) & $1,68^{\text {ns }}$ & $37,49^{* *}$ & $1,01^{\text {ns }}$ & $27,51^{* *}$ \\
Cr x Ds & $0,96^{\text {ns }}$ & $35,99^{* *}$ & $1,68^{\text {ns }}$ & $26,40^{* *}$ \\
\hline CV (\%) & 16,47 & 6,25 & 14,76 & 1,81 \\
\hline
\end{tabular}

(1)Dados transformados em arc sen $(\mathrm{x} / 100)^{0,5} \mathrm{e}$, nos parâmetros de extrato etéreo, foi somado o fator 100 antes da transformação dos

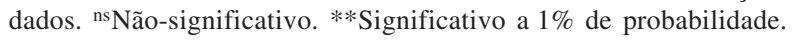


As densidades de estocagem avaliadas não influenciaram ( $p>0,05)$ a ERPB e a PGP (Tabela 4).

$\mathrm{O}$ grupo alimentado com a dieta suplementada com $18 \mathrm{mg} \mathrm{kg}^{-1}$ de cromo não diferiu estatisticamente dos animais suplementados com $6 \mathrm{mg} \mathrm{kg}^{-1}$ nem dos suplementados com $12 \mathrm{mg} \mathrm{kg}^{-1}$. Esse fato pode ser atribuído à possível toxicidade do produto, que interfere na eficiência verificada nas concentrações menores. Ou seja, a melhor concentração de carboquelato de cromo trivalente utilizada na ração foi de $12 \mathrm{mg} \mathrm{kg}^{-1}$.

Houve interação $(\mathrm{p}<0,01)$ entre as concentrações de cromo e as densidades de estocagem na variável retenção de gordura (Tabela 4). Houve interferência da densidade de estocagem sobre a exigência do cromo nessa variável (Tabela 5). Na maior densidade, houve maior retenção de gordura. O estresse aumenta a exigência nutricional do cromo, devido ao aumento da sua excreção na urina. $\mathrm{O}$ aumento na excreção reduz as reservas orgânicas de cromo, com consequientes alterações das respostas fisiológicas moduladas por esse mineral (Committee on Animal Nutrition, 1997).

A alta densidade é o agente estressor mais comum nas pisciculturas, resultando em diminuição do crescimento e produtividade devido à redução na utilização de nutrientes pelos peixes (Papoutsoglou et al., 1998). Observou-se que, na densidade mais alta, ocorreu menor eficiência de retenção de gordura nos peixes suplementados com $12 \mathrm{mg} \mathrm{kg}^{-1}$. Na densidade mais baixa, a exigência do mineral foi menor, da ordem de $6 \mathrm{mg} \mathrm{kg}^{-1}$, possibilitando menor retenção de gordura na

Tabela 5. Efeitos de interação entre as concentrações de cromo e as densidades de estocagem sobre a eficiência de retenção de extrato etéreo (EREE) e sobre a porcentagem de extrato etéreo no ganho de peso (EEGP) em juvenis de pacus ${ }^{(1)}$.

\begin{tabular}{|c|c|c|}
\hline \multirow[t]{2}{*}{ Níveis de cromo } & \multicolumn{2}{|c|}{ Densidades de estocagem } \\
\hline & $4 \mathrm{~kg} \mathrm{~m}^{-3}$ & $20 \mathrm{~kg} \mathrm{~m}^{-3}$ \\
\hline & \multicolumn{2}{|c|}{ EREE } \\
\hline $0 \mathrm{mg} \mathrm{kg}^{-1}$ & $90,00 \mathrm{Ac}$ & $90,00 \mathrm{Ab}$ \\
\hline $6 \mathrm{mg} \mathrm{kg}^{-1}$ & $34,30 \mathrm{Ba}$ & $90,00 \mathrm{Ab}$ \\
\hline $12 \mathrm{mg} \mathrm{kg}^{-1}$ & $57,44 \mathrm{Ab}$ & $65,70 \mathrm{Aa}$ \\
\hline $18 \mathrm{mg} \mathrm{kg}^{-1}$ & $90,00 \mathrm{Ac}$ & $83,57 \mathrm{Ab}$ \\
\hline & \multicolumn{2}{|c|}{ EEGP } \\
\hline $0 \mathrm{mg} \mathrm{kg}^{-1}$ & $90,00 \mathrm{Aa}$ & $90,00 \mathrm{Aa}$ \\
\hline $6 \mathrm{mg} \mathrm{kg}^{-1}$ & $74,45 \mathrm{Bb}$ & $90,00 \mathrm{Aa}$ \\
\hline $12 \mathrm{mg} \mathrm{kg}^{-1}$ & $77,93 \mathrm{Ab}$ & $80,77 \mathrm{Ab}$ \\
\hline $18 \mathrm{mg} \mathrm{kg}^{-1}$ & $90,00 \mathrm{Aa}$ & $87,81 \mathrm{Aa}$ \\
\hline
\end{tabular}

${ }^{(1)}$ Médias seguidas por letras iguais, minúsculas nas colunas e maiúsculas nas linhas, não diferem entre si pelo teste de Tukey, a $5 \%$ de probabilidade; dados transformados em $\operatorname{arc} \operatorname{sen}(\mathrm{x} / 100)^{0,5}$. carcaça. Assim, é possível que mudanças de exigência do nutriente sejam dependentes do patamar homeostático em que se encontra o organismo. O mesmo foi observado com a porcentagem de extrato etéreo no ganho de peso (Tabela 5), pois peixes alimentados com ração suplementada com $6 \mathrm{mg} \mathrm{kg}^{-1}$, na densidade mais baixa, apresentaram redução na porcentagem de gordura. Esse efeito pode ser benéfico para os consumidores, uma vez que a carne é mais magra. Porém o uso desse mineral deve ser estratégico, pois os lipídeos são essenciais para o metabolismo dos peixes.

Nas avaliações de EREE e de extrato etéreo no ganho de peso (EEGP) (Tabela 5), peixes suplementados com $18 \mathrm{mg} \mathrm{kg}^{-1}$ não apresentaram efeitos benéficos. Portanto esse fato deve ser reavaliado quanto à eventual ação tóxica ou antinutricional a partir dessa concentração.

\section{Conclusões}

1. Juvenis de Piaractus mesopotamicus alimentados com ração suplementada com até $12 \mathrm{mg} \mathrm{kg}^{-1}$ de cromo apresentam melhora na qualidade da carcaça.

2. Na densidade de estocagem de $4 \mathrm{~kg} \mathrm{~m}^{-3}$, o melhor nível de suplementação na dieta é de $6 \mathrm{mg} \mathrm{kg}^{-1}$ de cromo e, na densidade de $20 \mathrm{~kg} \mathrm{~m}^{-3}$, o melhor nível de suplementação de cromo na dieta é de $12 \mathrm{mg} \mathrm{kg}^{-1}$.

3. A suplementação com cromo é benéfica e possibilita a produção de carcaças mais magras e com mais proteína.

\section{Referências}

ALVES, J.M.C. Níveis de lipídeos em dietas para o crescimento inicial do pacu, Piaractus mesopotamicus (Holmberg, 1887). 1999. 57p. Dissertação (Mestrado) Universidade Estadual Paulista, Jaboticabal.

ASSOCIATION OF OFFICIAL ANALYTICAL CHEMISTS. Official methods of analysis of the Association of Official Analytical Chemists. 14.ed. Washington: AOAC, 1984. 1141p.

BRUM, C.D. Vitamina C favorece a formação de macrófagos policariontes em Piaractus mesopotamicus (Holmberg, 1887) mantidos em diferentes densidades. 2003. 58p. Dissertação (Mestrado) - Universidade Estadual Paulista, Jaboticabal.

BUREAU, D.P.; KIRKLAND, J.B.; CHO, C.Y. The effects of dietary chromium supplementation on performance, carcass yield, and blood glucose of rainbow trout (Oncorhynchus mykiss) fed two pratical diets. Journal of Animal Science, v.73, p.194, 1995. (Suppl.1).

CAZES, R.L. Cromo orgânico. A Hora Veterinária, n.19, 1999. 
COMITTEE ON ANIMAL NUTRITION. The role of chromium in animal nutrition. Washington: National Academy Press, 1997. $96 \mathrm{p}$.

FIGUEIREDO-GARUTTI, M.L. Carboidrato como fonte de energia e a ação do cromo trivalente e da insulina em pacu, Piaractus mesopotamicus (Pisces, Characidae). 1996. 90p. Dissertação (Mestrado) - Universidade Estadual Paulista, Jaboticabal.

FUJIMOTO, R.Y.; CASTRO, M.P.; MORAES, F.R.; GONÇALVES, F.D. Efeito da suplementação alimentar com cromo trivalente em Pacu, Piaractus mesopotamicus (Holmberg, 1887), mantido em diferentes densidades de estocagem: parâmetros fisiológicos. Boletim do Instituto de Pesca, v.31, p.155-162, 2005.

HASTEN, D.L.; HEGSTED, M.H.; KEENAN, M.J.; MORRIS, G.S. Effects of various forms of dietary chromium on growth and body composition in the rat. Nutrition Research, v.17, p.283-294, 1997.

HERTZ, Y.; MADAR, Z.; HEPHER, B.; GERTLER, A. Glucose metabolism in the common carp (Cyprinus carpio L.): the effects of cobalt and chromium. Aquaculture, v.76, p.255-267, 1989.

HOSSAIN, S.M.; BARRETO, S.L.; SILVA, C.G. Growth performance and carcass composition of broilers fed supplemental chromium from chromium yeast. Animal Feed Science and Technology, v.71, p.217-228, 1998.

KAATS, G.R.; BLUM, K.; PULLIN, D.; KEITH, S.C.; WOOD, R. A randomized, double-masked, placebo-controlled study of the effects of chromium picolinate supplementation on body composition: a replication and extension of a previous study. Current Therapeutic Research, v.59, p.379-388, 1998.

MORDENTI, A.; PIVA, A.; PIVA, G. The European perspective on organic chromium in animal nutrition. In: BIOTECHNOLOGY IN THE FEED INDUSTRY, 13., 1997, Nottingham, UK. Proceedings Alltech's Thistenth Annual Symposium. Nottingham: University Press, 1997. p.227-240.
MOWAT, D.N. Organic chromium in animal nutrition. Guelph: Chromium books, 1997.

OKADA, S.; TSUKADA, H.; OHBA, H. Enhancement of nucleolar RNA synthesis by chromium (III) in regenerating rat liver. Journal of Inorganic Biochemistry, v.21, p.113-124, 1984.

PAN, Q.; LIU, S.; TAN, Y.; BI, Y. The effect of chromium picolinate on growth and carbohydrate utilization in tilapia, Oreochromis niloticus x Oreochromis aureus. Aquaculture, v.225, p.421-429, 2003.

PAPOUTSOGLOU, S.E.; TZIHA, G.; VRETTOS, X.; ATHANASIOU, A. Effects of stocking density on behaviour and growth rate of european sea bass (Dicentrarchus labrax) juveniles reared in a closed circulated system. Aquacultural Engineering, v.18, p.138-144, 1998.

ROTLLANT, J.; PAVLIDIS, M.; KENTOURI, M.; ABAD, M.E.; TORT, L. Non-specific immune responses in the red porgy Pagrus pagrus after crowding stress. Aquaculture, v.156, p.279-290, 1997.

SANO, H.; KATO, Y.; TAKEBAYASHI, A.; SHIGA, A. Effects of supplemental chromium and isolation stress on the tissue responsiveness and sensitivity to insulin in sheep. Small Ruminant Research, v.33, p.239-246, 1999.

SHIAU, S.; LIN, S. Effect of suplemental dietary chromium and vanadium on the utilization of different carbohydrates in tilapia, Oreochromis niloticus x O. aureus. Aquaculture, v.110, p.321-330, 1993.

SHIAU, S.Y.; LIANG, H.S. Carbohydrate utilization and digestibility by tilapia, Oreochromis niloticus x $O$. aureus, are affected by chromic oxide inclusion in the diet. Journal of Nutrition, v.125, p.976-982, 1995.

STECH, M.R. Utilização de soja integral processada em dietas para o crescimento de pacu, Piaractus mesopotamicus (Holmberg, 1887). 1999. 90p. Dissertação (Mestrado) - Universidade Estadual Paulista, Jaboticabal.

$\overline{\text { Recebido em } 23 \text { de abril de } 2007 \text { e aprovado em 1o de novembro de } 2007}$ 